\title{
Investigation of the types and characteristics of the proteolytic enzymes formed by diverse strains of Proteus species
}

\author{
B. W. SENIOR
}

Department of Medical Microbiology, Dundee University Medical School, Ninewells Hospital, Dundee DD1 $95 Y$

\begin{abstract}
Many diverse clinical isolates of Proteus mirabilis (48 strains), $P$. penneri (25), $P$. vulgaris biogroup 2 (48) and $P$. vulgaris biogroup 3 (21) from man were examined for their ability to produce proteolytic enzymes and the nature and characteristics of the proteases were studied. All the $P$. penneri isolates, most $(94-90 \%)$ of the $P$. mirabilis and $P$. vulgaris biogroup 2 isolates, but only $71 \%$ of the $P$. vulgaris biogroup 3 isolates, secreted proteolytic enzymes. These were detected most readily at pH 8 with gelatin as substrate. A strong correlation was found between the ability of a strain to form swarming growth and its ability to secrete proteases. Non-swarming isolates invariably appeared to be non-proteolytic. However, some isolates, particularly of $P$. vulgaris biogroup 3, were non-proteolytic even when they formed swarming growth. Analysis of the secreted enzymes of the different Proteus spp. on polyacrylamide-gelatin gels under various constraints of $\mathrm{pH}$ and other factors showed that they were all EDTA-sensitive metalloproteinases. Analysis of the kinetics of production of the proteases revealed the formation of an additional protease of undefined type and function that was cellassociated and formed before the others were secreted. The secreted protease was subsequently modified to two isoforms whose mass $(53-46 \mathrm{kDa})$ varied with the Proteus spp. and the strain. There was no evidence that the secreted proteases of strains of Proteus spp. were of types other than metalloproteinases.
\end{abstract}

\section{Introduction}

All species of Proteus, except P. myxofaciens which has been isolated only from the larvae of the gypsy moth (Porthetria dispar), are widespread in nature and cause infections of the urinary tract, blood and wounds and other conditions in man [1]. P. mirabilis is the most frequently encountered species and is responsible for $c$. $70-90 \%$ of these infections. $P$. vulgaris and $P$. penneri cause similar types of infection because their habitats and virulence factors are similar. However, they are isolated less frequently and they may be less virulent.

Strains of Proteus spp. form several virulence factors [1]. One of them is a unique EDTA-sensitive metalloproteinase that cleaves at unique sites the heavy chain of $\mathrm{IgG}$, that of serum $\operatorname{IgA} 1$ and $\operatorname{IgA} 2$ and secretory $\operatorname{IgA} 1$ and $\operatorname{IgA} 2$, and also the secretory component in both its free and IgA-bound forms

Received 14 Sept. 1998; accepted 3 Nov. 1998. Corresponding author: Dr B. W. Senior.
[2-4]. Both active enzyme and cleaved antibody fragments can be detected in urine from patients with a proteus urinary tract infection showing that the enzyme is formed and is active in vivo [5]. The cleaved antibody fragments have defective immune effector functions and thereby the effectiveness of the immune response to the organism is limited [6]. The proteinase may also play a role in generating products such as glutamine, which is important in inducing swarm cell formation. In this complex process there is co-ordinate induction of various other virulence factors, including urease and haemolysin, so that the bacteria subsequently have the ability to invade cells $[7,8]$. In-vivo experiments in mice have shown that proteinase-negative mutants can infect the bladder, but have reduced ability to infect the kidney and form abscesses [9]. In view of the above and the wellestablished proteolytic capabilities of Proteus strains, the present study aimed to investigate the range and types of proteinase produced by Proteus spp. and to determine if they produced additional proteinases to those already described that might be important virulence factors. 


\section{Materials and methods}

\section{Bacteria}

A total of 142 isolates of Proteus spp. comprising $P$. mirabilis (48 isolates), P. penneri (25), $P$. vulgaris biogroup 2 (48) and $P$. vulgaris biogroup 3 (21) was studied. All were identified by standard procedures $[1,10]$ and were maintained in pure form on sealed nutrient agar slopes at $4^{\circ} \mathrm{C}$. All were clinical isolates from man and were selected in order that the group be as diverse as possible with regard to site of isolation, bacteriocin production (p)/sensitivity (s) type [11, 12], $\mathrm{O}$ serotype and country of origin.

\section{Detection of proteolytic activity of strains}

The proteolytic activity of isolates was examined on three media. All contained Cystine Electrolyte Deficient Medium (CLED, Oxoid CM 301) 3.6\% w/v in

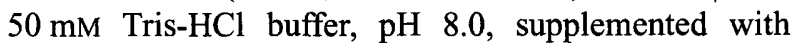
casein (Sigma) $1 \% \mathrm{w} / \mathrm{v}$ (casein medium), or gelatin (Sigma, 300 bloom) 1\% w/v (gelatin medium) or skim milk $2 \% \mathrm{w} / \mathrm{v}$ (milk medium). These media were sterilised by autoclaving at $121^{\circ} \mathrm{C}$ for $15 \mathrm{~min}$. In the preparation of the milk medium, the skim milk supplement was added aseptically to the sterile basal medium from a stock of Skim Milk Powder (Oxoid L31) $20 \% \mathrm{w} / \mathrm{v}$ in water which had been sterilised by heat at $121^{\circ} \mathrm{C}$ for $5 \mathrm{~min}$.

The strains were inoculated by loop on to plates of these media from nutrient broth cultures which had been incubated overnight at $37^{\circ} \mathrm{C}$. The plates were incubated in air at $37^{\circ} \mathrm{C}$ and examined for proteolytic activity after $16 \mathrm{~h}$. This was revealed as a zone of clearing around the growth of the strain. Addition of $1 \mathrm{~N} \mathrm{HCl}$ to the casein medium, or mercuric chloride $15 \% \mathrm{w} / \mathrm{v}$ in $1 \mathrm{~N} \mathrm{HCl}$ to the gelatin medium plates, enhanced the definition of the zone of proteolysis if this was not clear. If zones of proteolysis were not seen the plates were re-incubated for up to $48 \mathrm{~h}$.

\section{Production of protease preparations}

Initially these were prepared as described previously [2]. Essentially they were the supernates from suspensions in $50 \mathrm{mM}$ Tris- $\mathrm{HCl}$ buffer ( $\mathrm{pH} 8.0$ ) containing sodium azide $0.04 \% \mathrm{w} / \mathrm{v}$, of bacteria grown overnight at $37^{\circ} \mathrm{C}$ on sterile dialysis tubing membranes overlying blood agar (Blood Agar Base, Oxoid CM 55, supplemented with horse blood $5 \% \mathrm{v} / \mathrm{v}$ ) and centrifuged at $11600 \mathrm{~g}$ for $2 \mathrm{~min}$. Subsequent experimentation showed that identical protease preparations could be prepared more simply by taking the supernates from cultures of bacteria that had been grown at $37^{\circ} \mathrm{C}$ for an appropriate period in nutrient broth (Nutrient Broth No. 2; Oxoid CM67) with shaking, and centrifuged, and adding sodium azide to $0.04 \%$. Protease preparations were stored at $-20^{\circ} \mathrm{C}$.

\section{Assay of proteolytic activity}

The enzyme preparation $(10 \mu \mathrm{l})$ was added to a microcentrifuge tube containing $65 \mu \mathrm{l}$ of $50 \mathrm{mM}$ Tris$\mathrm{HCl}, \mathrm{pH} 8.0$, with sodium azide $0.04 \% \mathrm{w} / \mathrm{v}$ and azocasein $50 \mu \mathrm{l}(5 \mathrm{mg} / \mathrm{ml}$ of distilled water). The mixture was incubated in a water bath at $37^{\circ} \mathrm{C}$ for $1 \mathrm{~h}$ and the reaction was terminated by adding two volumes, i.e., $250 \mu \mathrm{l}$, of trichloroacetic acid $5 \% \mathrm{w} / \mathrm{v}$. After standing for a few minutes at room temperature during which time the undigested azocasein was precipitated, the tubes were centrifuged at $11600 \mathrm{~g}$ for $1 \mathrm{~min}$ and the clear supernate was removed to a cuvette holding three volumes, i.e., $375 \mu \mathrm{l}$, of $0.5 \mathrm{M}$ $\mathrm{NaOH}$. The absorption of the reaction at $440 \mathrm{~nm}$ was measured against a water blank. One unit of protease was defined as that activity hydrolysing $1 \mathrm{mg}$ of azocasein $/ \mathrm{h}$ at $37^{\circ} \mathrm{C}$ and was calculated from the equation:

number of units of protease $=$

$\mathrm{E}_{440}$ of reaction $\times 60 / 1.65 \times$ reaction time $(\mathrm{min})$.

\section{PAGE analysis of protease}

Samples containing $c$. 0.01 unit of protease were added to an equal volume of sample buffer $(0.125 \mathrm{M}$ Tris$\mathrm{HCl}, \mathrm{pH} 6.8$, containing glycerol $20 \%$, SDS $2 \%$, mercapto-ethanol $10 \%$ and a trace of bromophenol blue dye) and loaded on to a stacking gel of acrylamide (4\%) in $0.125 \mathrm{M}$ Tris- $\mathrm{HCl}(\mathrm{pH} 6.8)$ containing SDS $0.1 \%$ overlying a separating gel of acrylamide $(11 \%)$ in $0.375 \mathrm{M}$ Tris- $\mathrm{HCl}(\mathrm{pH} 8.8)$ containing SDS $0.2 \%$ to which molten but cool gelatin (Sigma, 300 bloom) $1 \%$ $\mathrm{w} / \mathrm{v}$ in $50 \mathrm{mM}$ Tris- $\mathrm{HCl}(\mathrm{pH} 8.0)$ containing sodium azide $0.04 \% \mathrm{w} / \mathrm{v}$ was added to $0.1 \% \mathrm{w} / \mathrm{v}$ before polymerisation. The anode buffer was Tris $1.21 \% \mathrm{w} / \mathrm{v}$ and SDS $0.1 \% \mathrm{w} / \mathrm{v}(\mathrm{pH} 8.1)$ and the cathode buffer was Tris $0.63 \% \mathrm{w} / \mathrm{v}$, glycine $0.39 \% \mathrm{w} / \mathrm{v}$, SDS $0.1 \%$ $\mathrm{w} / \mathrm{v}(\mathrm{pH} 8.9$ ). After electrophoresis at $12 \mathrm{~mA}$ for $16 \mathrm{~h}$ the SDS was removed from the gel by gently washing the gel at $4^{\circ} \mathrm{C}$ for $1 \mathrm{~h}$ in $500 \mathrm{ml}$ of Triton X100 2.5\% $\mathrm{v} / \mathrm{v}$ in distilled water. The washing process was repeated. The gel was then immersed in the appropriate buffer (usually $50 \mathrm{mM}$ Tris- $\mathrm{HCl}, \mathrm{pH} 8.0$ ) and incubated for $4 \mathrm{~h}$ at $37^{\circ} \mathrm{C}$. The gel was then stained in Coomassie Blue R250 $0.125 \% \mathrm{w} / \mathrm{v}$ in methanol $50 \% \mathrm{v} / \mathrm{v}$ in aqueous acetic acid $10 \% \mathrm{v} / \mathrm{v}$ for $2 \mathrm{~h}$ and de-stained overnight in several changes of aqueous methanol $10 \%$ $\mathrm{v} / \mathrm{v}$, acetic acid $10 \% \mathrm{v} / \mathrm{v}$. Protease bands were revealed as unstained areas of degraded protein against a blue background of undegraded stained gelatin.

\section{Results}

\section{Proteolytic activity of strains of Proteus spp.}

The proteolytic activity of 142 isolates of Proteus spp. was determined on milk, gelatin and casein media and $128(90 \%)$ were found to be proteolytic on all these media. These included all the 25 isolates of $P$. penneri, 
$45(94 \%)$ of the 48 isolates of P. mirabilis, $43(90 \%)$ of the 48 isolates of $P$. vulgaris biogroup 2 and $15(71 \%)$ of the 21 isolates of $P$. vulgaris biogroup 3. Most of these isolates showed wide zones of proteolysis after incubation for $16 \mathrm{~h}$ at $37^{\circ} \mathrm{C}$. Generally, and irrespective of the organism, proteolytic zones were seen most readily on milk medium, but zones were bigger on gelatin than on casein medium. A few isolates appeared to be non-proteolytic at this stage, but on incubation for a further $32 \mathrm{~h}$, smaller zones of proteolysis were formed by some, whereas others remained apparently non-proteolytic.

\section{Proteolytic activity and swarming growth}

The 14 isolates of Proteus spp. that appeared to be non-proteolytic or proteolytic on only some of the media were examined further. Their nutrient broth cultures were plated out for single colonies on CLED. After incubation overnight at $37^{\circ} \mathrm{C}$, several (9-14) well-isolated colonies of each isolate were picked with a sterile straight wire and each was inoculated on to four plates: blood agar, CLED, gelatin medium and casein medium. The blood agar and CLED plates were incubated at room temperature $\left(c .22^{\circ} \mathrm{C}\right)$ for several days and examined for swarming growth. The gelatin and casein media plates were incubated overnight at $37^{\circ} \mathrm{C}$ and examined for zones of proteolysis.

All the colonies of each of six isolates (one $P$. mirabilis, three $P$. vulgaris biogroup 2 and two $P$. vulgaris biogroup 3) were unable to form swarming growth on blood agar and all were also unable to degrade gelatin or casein. All the colonies of each of another four isolates (one $P$. mirabilis, two $P$. vulgaris biogroup 2 and one $P$. vulgaris biogroup 3) swarmed on blood agar and degraded both gelatin and casein, whereas all the colonies of another two isolates (one $P$. mirabilis and one $P$. vulgaris biogroup 3) produced swarming growth and degraded gelatin but not casein. For the remaining two isolates (both of $P$. vulgaris biogroup 3), some of the isolated colonies produced swarming growth on blood agar, others did not. All the colonies of strain $12329 \mathrm{~N}$ that swarmed degraded both gelatin and casein, whereas all the colonies that did not swarm degraded neither gelatin nor casein. All the colonies of strain PB 53 that swarmed degraded gelatin but not casein, whereas all the colonies that did not swarm degraded neither protein substrate.

Thus, a clear association was found between the ability of strains to swarm and their ability to form a proteolytic enzyme. Examination of colonies of a pure culture of $P$. mirabilis strain 64676 after plating out and incubation overnight at $37^{\circ} \mathrm{C}$ on milk medium supported this conclusion (Fig. 1). Colonies showing the onset of swarming were surrounded by a zone of degraded casein; this zone was not seen around those colonies that had not yet commenced swarming growth. Isolates of Proteus spp. that were unable to form swarming growth were invariably unable to produce proteases and degraded neither gelatin nor casein. Isolates that swarmed usually degraded both gelatin and casein but a few, most of which appeared to be weak protease producers, degraded gelatin but not casein.

\section{The effect of $\mathrm{pH}$ on protease activity}

Nutrient broth culture supernates of one representative isolate of $P$. mirabilis, $P$. vulgaris biogroup $2, P$. vulgaris biogroup 3 and $P$. penneri were each applied five times to wells equally spaced across an acryla-

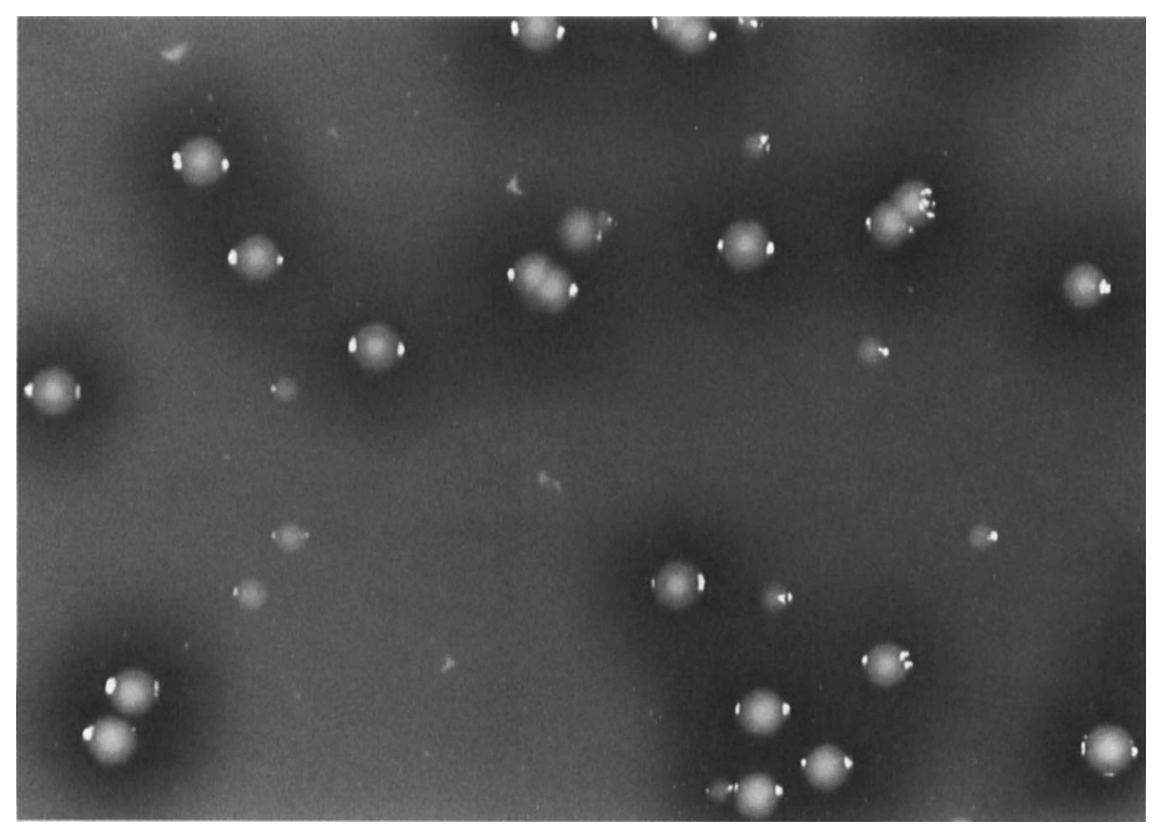

Fig. 1. Early swarming (large) and non-swarming (small) variant colonies of P. mirabilis strain 64676 after overnight incubation at $37^{\circ} \mathrm{C}$ on milk medium. A zone of degraded casein produced by the action of secreted proteolytic enzymes surrounds the growth of the swarming colonies; this was not formed by the non-swarming colonies. 
mide-gelatin gel after overnight incubation at $37^{\circ} \mathrm{C}$ and assay for proteolytic activity. After electrophoresis and washing as above, the gel was sliced into five segments, each containing the proteases of all the different organisms. A segment was placed in each of the following five buffers: $0.1 \mathrm{M}$ glycine- $\mathrm{HCl}(\mathrm{pH} \mathrm{2.0})$; $0.1 \mathrm{M}$ sodium acetate-acetic acid $(\mathrm{pH} 4.0)$ containing $1 \mathrm{mM}$ dithiothreitol; $0.1 \mathrm{M}$ sodium acetate-acetic acid $(\mathrm{pH} 5.0) ; 0.1 \mathrm{M}$ sodium phosphate $(\mathrm{pH} 6.0)$ and $0.1 \mathrm{M}$ Tris- $\mathrm{HCl}(\mathrm{pH} 8.0)$. After equilibration at $4^{\circ} \mathrm{C}$ for $1 \mathrm{~h}$, the gel segments were incubated in the different buffers at $37^{\circ} \mathrm{C}$ for $4 \mathrm{~h}$ and then stained. Several bands of protease produced by the different organisms were detected in gel segments incubated in buffers at $\mathrm{pH} 5$, 6 and 8 . The protease bands were more pronounced at $\mathrm{pH} 8$ than at $\mathrm{pH} 5$ or 6 , but they were no different in number or position at $\mathrm{pH} 5$ or 6 than at $\mathrm{pH} 8$. No protease bands were detected at $\mathrm{pH} 2$ or 4 . These results indicate that Proteus proteases were probably of a single class. They were unlikely to be either carboxypeptidases with a $\mathrm{pH}$ optimum of $2-5$, or thiol proteases activated by dithiothreitol with a $\mathrm{pH}$ optimum of 4-7; they were more likely to be either serine- or metallo-proteinases with a $\mathrm{pH}$ optimum of 7-9. Further experiments showed that the protease activity of each preparation, as determined by the azocasein assay, was inhibited by $10 \mathrm{mM}$ EDTA. These results indicate that the proteases of all Proteus spp. were metalloproteinases with an optimum $\mathrm{pH}$ of $c$. 8 . Further studies were always performed at this $\mathrm{pH}$.

\section{Comparison of gelatin and casein as substrates}

Protease preparations from eight representative isolates of all the different Proteus spp. (including those that degraded both gelatin and casein and those that degraded gelatin alone) were electrophoresed on a polyacrylamide gel, half of which contained gelatin $0.1 \%$ as substrate and the other half contained casein $0.1 \%$. After electrophoresis, washing, development at $\mathrm{pH} 8$ and staining as above, it was found that although different isolates of some of the Proteus spp. produced protease bands of slightly different electrophoretic mobility, for all the isolates, the number and position of their protease bands were the same on both the gelatin fraction of the gel and the casein fraction. This was true even for the two isolates that degraded gelatin but not casein on petri dishes. However, for all the isolates, the bands appeared to have a greater intensity on gelatin than casein. This result indicated that the protease enzymes of Proteus spp. that degrade gelatin had the same electrophoretic mobility as those that degrade casein and that gelatin was the more sensitive substrate. Therefore, gelatin was used in preference to casein in all further work.

\section{Electrophoretic analysis of proteases}

$P$. mirabilis. The protease enzymes (present in the supernates of nutrient broth cultures incubated for $16 \mathrm{~h}$ at $37^{\circ} \mathrm{C}$ ) of 18 diverse $P$. mirabilis isolates, selected at random from the 48 proteolytic isolates, were analysed by electrophoresis on polyacrylamide-gelatin gels. All produced two protease bands of the same electrophoretic mobility. $P$. mirabilis strain 64676 was selected as the representative strain for $P$. mirabilis protease. Subsequent comparison by electrophoresis of purified protease from $P$. mirabilis strain 64676 [13] with that of the crude enzyme of the same strain from nutrient broth culture supernates and that of the supernates of the washings of cells grown on dialysis membranes on blood agar plates indicated that the mobilities of the two protease bands present in the pure enzyme were indistinguishable from those in both preparations of the crude enzyme.

Studies on the kinetics of formation of $P$. mirabilis 64676 protease in culture supernates and that remaining associated with the cells after they had been washed in buffer and lysed, showed that in early log phase (after incubation for $4 \mathrm{~h}$ ), a cell-associated (probably internal) protease was detectable shortly before greater amounts of three slightly more mobile bands of protease appeared in the supernate (Fig. 2). Over the next $16 \mathrm{~h}$, the cell-associated protease never appeared in the supernate and its amount did not increase. However, the protease bands in the supernate appeared to be modified, the least mobile band being replaced in time with increasing but equal amounts of two more mobile protease bands. Prolonged incubation up to $48 \mathrm{~h}$ showed that these two protease bands, of $c$. 53 and $50 \mathrm{kDa}$, continued to be formed in increasing amounts and their mobilities remained unchanged.

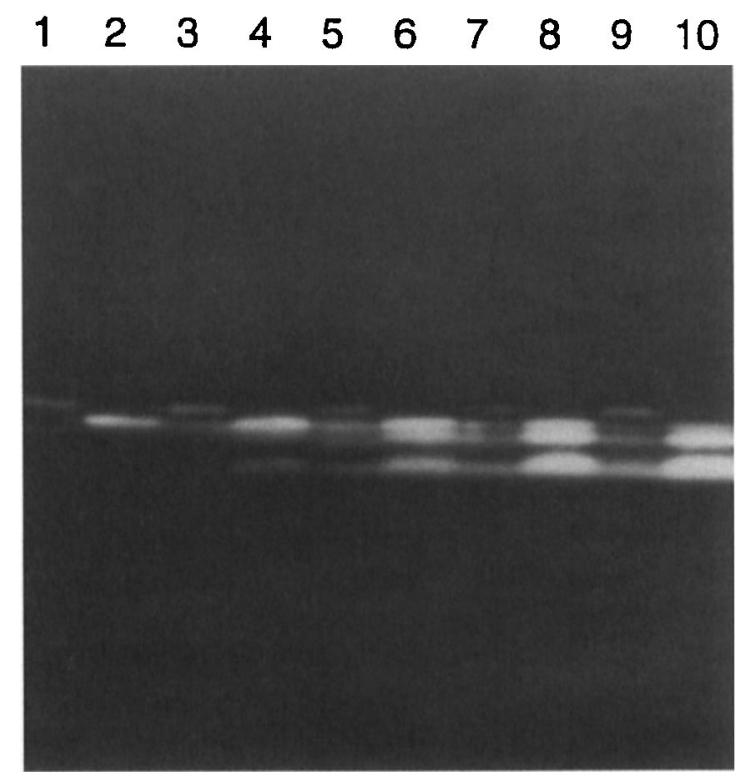

Fig. 2. The kinetics of protease formation by $P$ mirabilis strain 64676 growing in nutrient broth at $37^{\circ} \mathrm{C}$ and sampled after $4,5,6,7$ and $8 \mathrm{~h}$. Lanes $1,3,5,7,9$, cellassociated protease bands; $2,4,6,8,10$, secreted protease bands in culture supernates. 
P. penneri. Polyacrylamide-gelatin gel electrophoresis of the protease enzymes (present in the supernates of nutrient broth cultures incubated for $16 \mathrm{~h}$ at $37^{\circ} \mathrm{C}$ ) of 18 diverse isolates of $P$. penneri selected at random from the collection of 25 isolates showed that all formed two protease bands of $c .50$ and $48 \mathrm{kDa}$. These were of the same mobility in all the isolates examined. $P$. penneri strain $05665 \mathrm{~V}$ was selected as the representative strain for $P$. penneri protease.

P. vulgaris biogroup 2 and 3. Polyacrylamide-gelatin gel electrophoresis of the protease enzymes present in the supernates of 16-h nutrient broth cultures incubated at $37^{\circ} \mathrm{C}$ of 26 diverse isolates selected at random from the 43 proteolytic $P$. vulgaris biogroup 2 isolates showed that all strains produced two protease bands. These were all of the same mobility except for two isolates whose protease bands were slightly more mobile. Strains $60694 / 78$ (protease bands of $c .51$ and $49 \mathrm{kDa}$ ) and $72640 \mathrm{~B}$ (protease bands of c. 50 and $48 \mathrm{kDa}$ ) were selected as the representative strains of the standard mobility and faster mobility protease-producing strains of $P$. vulgaris biogroup 2 , respectively.

The same analysis of similar protease preparations from 10 isolates selected at random from the $15 P$. vulgaris biogroup 3 isolates that degraded gelatin and casein and from two isolates that degraded gelatin but not casein showed that all produced two protease bands, but there was a little more variation in their mobilities than that seen with the other Proteus spp. $P$. vulgaris biogroup 3 strains $02987 \mathrm{~W}$ (protease bands of c. 53 and $50 \mathrm{kDa}$ ) and F57812 (protease bands of c. 49 and $46 \mathrm{kDa}$ ) had the least mobile and the most mobile protease bands, respectively.

A comparison of the range of mobilities of the protease bands of representatives of the different Proteus spp. is presented in Fig. 3. From this it can be seen that although in general, the mobilities of the protease bands of Proteus spp. were similar, those of $P$. mirabilis were less mobile than those of $P$. vulgaris biogroup 2 and $P$. penneri strains. The protease bands of $P$ vulgaris biogroup 3 strains ranged from those with a mobility similar to those of $P$. mirabilis strains, to others which were the most mobile bands seen in the genus. The protease bands of $P$. penneri strains were of a mobility similar to that of the faster protease bands of $P$. vulgaris biogroup 2 strains and some of those of biogroup 3 . It was noted that the protease bands of $P$. mirabilis strain SW 49 and $P$. vulgaris biogroup 3 strain PB53, that degraded gelatin but not casein, were of the same number and mobility as those of other strains of the same species that degraded both gelatin and casein.

\section{Discussion}

In nature, strains of Proteus spp. - unlike the other members of the Proteeae - are associated with
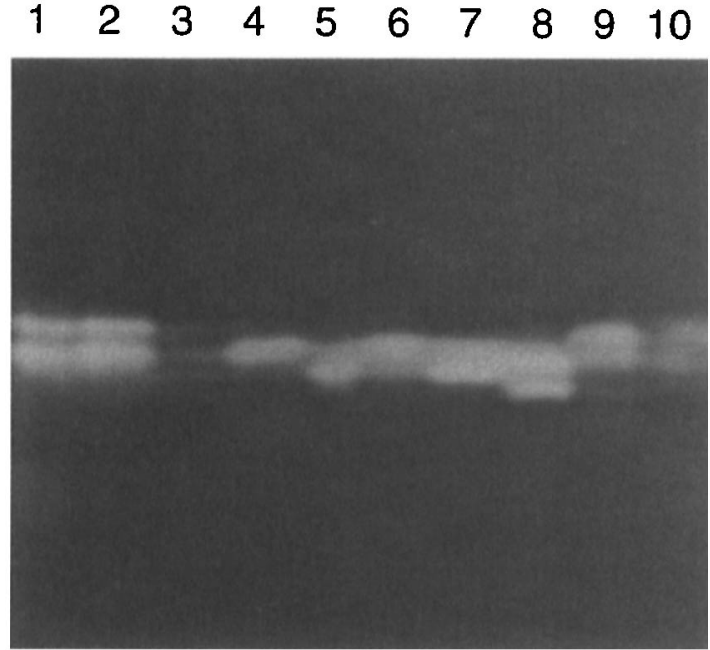

Fig. 3. The range of mobility of the secreted proteolytic enzymes of different strains of Proteus spp. after electrophoresis and development of acrylamide-gelatin gels. Lanes 1-3, P. mirabilis strains F59242, 64676, SW $49 ; 4-6, P$. vulgaris biogroup 2 strains $60694 / 78$, $72640 \mathrm{~B}, \mathrm{~F} 34393 / 77 \mathrm{~A} ; 7$, P. penneri strain $05665 \mathrm{~V} ; 8$ 10, $P$. vulgaris biogroup 3 strains $\mathrm{F} 57812$, 02987W, PB 53. Strains SW49 and PB53 degraded gelatin but not casein; all the other strains degraded both substrates.

decomposing animal and vegetable material. Therefore, it is not surprising that they are the only members of the tribe that form proteolytic enzymes [1]. Because one of the enzymes has been shown to be a unique metalloproteinase that is an important virulence factor of Proteus spp. in infections of man $[1,2,5,6]$, and protease negative strains have reduced ability to infect the kidney and form abscesses [9], it was thought important to investigate the full range of secreted proteases formed by members of the genus to determine if there were other proteolytic enzymes that might also act as virulence factors in proteus infections of man. Thus all the strains examined were clinical isolates of diverse types from man.

As was anticipated, most isolates were found to produce proteolytic enzymes. However, it was surprising to find that all $25 \mathrm{P}$. penneri isolates examined were proteolytic after incubation for $16 \mathrm{~h}$, because Hickman et al. [14] found that only $20 \%$ of 25 isolates of $P$. penneri were proteolytic at $24 \mathrm{~h}$ and even after incubation for 7 days, only $75 \%$ were proteolytic. The lowest proportion of proteolytic strains was found among $P$. vulgaris strains of biogroup 3. Subsequent studies (personal unpublished data) of more strains of this group have shown an even greater proportion to be non-proteolytic than was found in this study. This diversity within $P$ vulgaris biogroup 3 strains supports the view that $P$. vulgaris strains of biogroup 3 comprise several genomospecies. Indeed, four distinct DNA groups have been found among biogroup 3 strains by hybridisation tests [15].

The results also indicate that tests for protease activity by Proteus spp. need to be carefully controlled. 
Gelatin was found to be a more sensitive substrate than casein and the reactions needed to be performed at c. $\mathrm{pH}$ 8. The ability of an isolate to produce proteolytic enzymes was closely associated with its ability to form swarming growth. Thus, isolates that were unable to form swarming growth did not secrete proteolytic enzymes and appeared to be non-proteolytic. They remained like this until such time as the strains were able to form swarming growth; at this stage proteolytic activity became detectable. The work of others [8] supports this association between swarm cell formation and protease production. However, it should be noted that swarming growth is not always associated with protease production because some swarming strains of $P$ vulgaris of biogroup 3, developed after repeated subcultures of their nonswarming parents, do not produce proteolytic enzymes (personal unpublished observations).

The secreted proteolytic enzymes of most strains of Proteus spp. degraded both gelatin and casein. However, those of a few strains degraded gelatin but not casein. The fact that the mobility and number of the protease bands on gels containing gelatin or casein were the same for strains that degraded both gelatin and casein as for those that degraded gelatin but not casein suggests that the proteases produced by the latter strains were not different from those produced by the former group of strains. The inability of some Proteus strains that degrade gelatin to degrade casein is believed to be the outcome of weaker protease production and a less sensitive substrate.

Analysis of culture supernates for proteases of different classes by development of gels under different constraints of $\mathrm{pH}$ and other factors revealed that only one class of proteolytic enzyme - EDTA-sensitive metalloproteinases - was produced by Proteus spp. Comparison of the electrophoretic mobility of the crude protease of $P$. mirabilis strain 64676 present in broth culture supernates with that of the purified metalloproteinase from the same strain showed them to be indistinguishable and thus proteins of $c .53$ and $50 \mathrm{kDa}$ [13]. The secreted metalloproteinase enzymes of the other Proteus spp. also appeared as two protease bands of equal intensity (c. $46-53 \mathrm{kDa}$ depending upon the strain).

Kinetic studies of protease production in $P$. mirabilis revealed the appearance of a cell-associated (probably internal) protease that was both less mobile and was formed before the protease that was detectable in the supernate. Furthermore, it appeared to remain cell associated. The properties and function of this cellassociated protease are unknown, but it is possible that it may be of a different class of protease from the secreted metalloproteinases. It may have a role in the secretion and processing of the secreted proteases and be important in the process of invasion of mammalian cells by swarming Proteus cells in which this protease is formed early, and later also within the penetrated cell. These matters are to be investigated further.

The bands of secreted protease changed in both size and number with time, suggesting that there was some auto-digestion until the two protease bands of equal activity were formed. Evidence from a previous study [13] suggests that these are isoforms of the same protease. Thus, it would appear that proteolytic strains of Proteus spp. secrete only one kind of proteinase. This is an EDTA-sensitive metalloproteinase which appears as two bands of slightly different size (53$46 \mathrm{kDa}$ ) among the strains of various Proteus spp.

\section{References}

1. Senior BW. Proteus, Morganella, and Providencia. In: Balows A, Duerden BI (eds) Topley \& Wilson's Microbiology and microbial infections, 9th edn, vol 2. Systematic bacteriology. London, Arnold. 1998: 1035-1050.

2. Senior BW, Albrechtsen M, Kerr MA. Proteus mirabilis strains of diverse type have IgA protease activity. J Med Microbiol 1987; 24: 175-180.

3. Senior BW, Albrechtsen M, Kerr MA. A survey of IgA protease production among clinical isolates of Proteeae. $J$ Med Microbiol 1988; 25: 27-31.

4. Loomes LM, Senior BW, Kerr MA. A proteolytic enzyme secreted by Proteus mirabilis degrades immunoglobulins of the immunoglobulin $\mathrm{Al}$ ( $\mathrm{IgA} 1$ ), IgA2, and $\mathrm{IgG}$ isotypes. Infect Immun 1990; 58: 1979-1985.

5. Senior BW, Loomes LM, Kerr MA. The production and activity in vivo of Proteus mirabilis IgA protease in infections of the urinary tract. J Med Microbiol 1991; 35: 203-207.

6. Loomes LM, Kerr MA, Senior BW. The cleavage of immunoglobulin $\mathrm{G}$ in vitro and in vivo by a proteinase secreted by the urinary tract pathogen Proteus mirabilis. J Med Microbiol 1993; 39: 225-232.

7. Allison C, Lai H-C, Gygi D, Hughes C. Cell differentiation of Proteus mirabilis is initiated by glutamine, a specific chemoattractant for swarming cells. Mol Microbiol 1993; 8: $53-60$.

8. Allison C, Lai C-H, Hughes C. Co-ordinate expression of virulence genes during swarm-cell differentiation and population migration of Proteus mirabilis. Mol Microbiol 1992; 6: 1583-1591.

9. Allison C, Emödy L, Coleman N, Hughes C. The role of swarm cell differentiation and multicellular migration in the uropathogenicity of Proteus mirabilis. J Infect Dis 1994; 169: 1155-1158.

10. Senior BW. Media and tests to simplify the recognition and identification of members of the Proteeae. J Med Microbiol 1997; 46: 39-44.

11. Senior BW. Typing of Proteus strains by proticine production and sensitivity. $J$ Med Microbiol 1977; 10: 7-17.

12. Senior BW. The ability of a Proteus mirabilis strain to invade the bloodstream is independent of its proticine production/ proticine sensitivity type. $J$ Med Microbiol 1997; 46: 407-412.

13. Loomes LM, Senior BW, Kerr MA. Proteinases of Proteus spp.: purification, properties, and detection in urine of infected patients. Infect Immun 1992; 60: 2267-2273.

14. Hickman FW, Steigerwalt AG, Farmer JJ, Brenner DJ. Identification of Proteus penneri sp. nov., formerly known as Proteus vulgaris indole negative or as Proteus vulgaris biogroup 1. J Clin Microbiol 1982; 15: 1097-1102.

15. O'Hara C, Hickman-Brenner F, Steigerwalt A et al. Proteus vulgaris DNA groups 3, 4, 5, and 6. 94th General Meeting of the American Society for Microbiology. Las Vegas, 1994; 535, Abstract C-253. 